5 Sibert JR, Maddocks GB, Brown BM. Childhood accidents-an endemic of epidemic proportions. Arch Dis Child 1981;56: 225-34.

${ }^{6}$ Manciaux M. 'Some monographs' in children and accidents. Children in the tropics 1980;123:6-10.

${ }^{7}$ Mero Asagba GEE. Three villages' memory of accidents involving children in three generations. (Dissertation). London: Institute of Child Health, November 1982.

Correspondence to Dr D Simmons. 1 The Pennards, French Street, Sunbury on Thames, TW17 5JX

Received 3 August 1984

\title{
Re-evaluation of saliva for monitoring theophylline concentrations
}

\author{
G W RYLANCE, D T BESWICK, R E CULLEN, AND D G V ROBERTS \\ Children's Hospital, Ladywood Middleway, Birmingham
}

SUMMARY Variability of the mixed saliva/plasma theophylline relation was examined in seven children aged 2 to 13 years. Good correlation between plasma and saliva concentrations was found, but on the three occasions there was considerable interand intrapatient variability. There was no significant or consistent relation between unstimulated and stimulated saliva concentrations or between saliva concentrations and sample volumes. Plasma theophylline concentrations cannot be predicted accurately from saliva values.

Theophylline is an effective bronchodilator for both acute medical treatment and prophylaxis of asthma. Bronchodilator effect and toxicity are closely related to plasma concentration, and optimum treatment in adults is usually achieved when the plasma theophylline concentration is maintained within the range 10 to $20 \mathrm{mg} / \mathrm{l}(55$ to $110 \mu \mathrm{mol} / \mathrm{l}){ }^{1}$ This therapeutic range has not been confirmed in children, although decreased symptoms have been noted in a group of children when concentrations averaged $13 \mathrm{mg} / \mathrm{l}(67$ $\mu \mathrm{mol} / \mathrm{l})$ compared with a mean value below $10 \mathrm{mg} / \mathrm{l}^{2}$

There are large intersubject differences in theophylline pharmacokinetics in children. Plasma theophylline concentrations need to be monitored, therefore, in order to establish the dose required to achieve concentrations within the therapeutic range, which, it is assumed, is equally applicable to children.

Saliva sampling is used to monitor drug concentrations of some anticonvulsants, ${ }^{3}$ and its use to monitor theophylline has been suggested. ${ }^{45}$ The evidence in the published reports, however, does not always support this view. ${ }^{67}$ This study aimed to examine the validity of using saliva for monitoring theophylline by examining the effects on the saliva/ plasma theophylline ratio of certain factors known to affect the saliva/plasma relation of drugs generally.

\section{Methods}

Seven children aged 2 to 13 years were included in the study, which had been approved by our local research ethical committee: informed parental consent was obtained. None of the children had liver or kidney disease, and none were receiving drugs known to affect theophylline disposition. No attempt was made to minimise dietary xanthines on the day before or during the study periods.

Each child was studied on three separate occasions. Firstly, after a constant rate infusion into a peripheral vein of approximately $3.5 \mathrm{mg} / \mathrm{kg}$ aminophylline ( $79 \%$ theophylline, $21 \%$ ethylene diamine) over 20 minutes. Two saliva samples (one unstimulated, one stimulated by citric acid crystals) and a venous blood sample $(1 \mathrm{ml}$ - via an indwelling heparinised catheter) were obtained before and at hourly intervals for 10 hours after completion of the infusion. Saliva samples were collected in children aged under 4 years by a mucus extractor, and older children were asked to spit into a container until approximately 2 to $4 \mathrm{ml}$ of mixed saliva was collected. Thorough mouth washing took place before and after each sampling.

The children were then studied on two subsequent occasions during regular, oral sustained release aminophylline or theophylline treatment given in equal 12 hourly doses at 8 am and $8 \mathrm{pm}$. Six children received Phyllocontin (Napp Laboratories) and one received Theo Dur (Fisons). Each study was within two weeks and after at least five days of the preceding study, and on each occasion hourly samples (two saliva, one blood as above) were collected between morning and evening doses. The weight related dose increased with time and was different on each occasion within each individual.

The volumes of the saliva samples were measured and the samples centrifuged and stored at $-20^{\circ} \mathrm{C}$ until assayed for theophylline (EMIT (Syva)). The lower limit of the assay was $1.0 \mathrm{mg} / \mathrm{l}(5.5 \mu \mathrm{mol} / \mathrm{l})$. The within run and between run coefficients of 


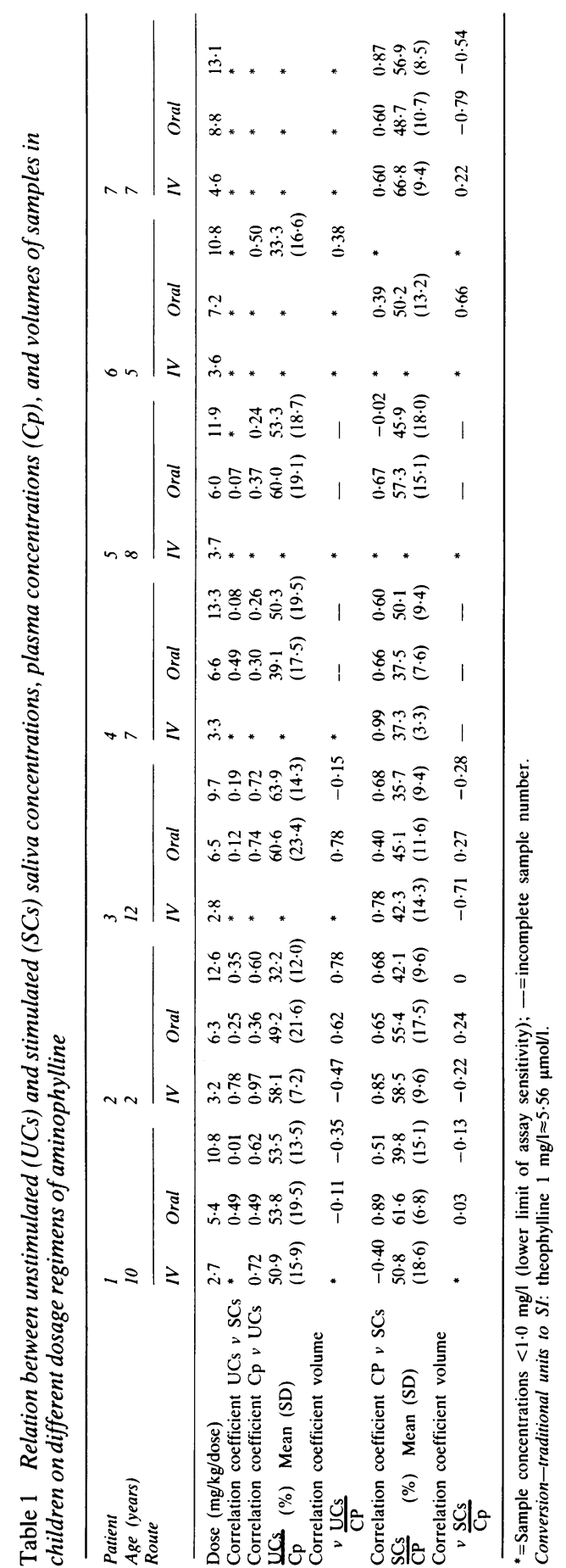

variation for the assay were $2.5 \%(\overline{\mathrm{x}}=15.0 \mathrm{mg} / \mathrm{l}$, $\mathrm{n}=10)$ and $5 \cdot 8 \%(\overline{\mathrm{x}}=15 \cdot 0 \mathrm{mg} / \mathrm{l}, \mathrm{n}=10)$ respectively.

\section{Results}

The results are shown in Table 1. Despite a highly significant correlation between the plasma theophylline concentration and saliva theophylline concentration (stimulated and unstimulated) $(\mathrm{r}=0.79$, $\mathrm{n}=224, \mathrm{P}<0.001)$, there was marked inter- and intrasubject variability in the correlation coefficients calculated from data on the three separate occasions. The saliva/plasma ratio varied both between and within subjects. This ratio (expressed as a percentage) varied between $32.2 \%$ and $66 \cdot 8 \%$.

There was no significant or consistent relation between the stimulated and unstimulated saliva concentration, as shown by the poor and variable correlation coefficients between the two parameters (Table 1). Neither was there any consistent relation between sample volume and saliva concentration, nor between the time from dosing and the saliva/ plasma ratio.

The relation between sample type and plasma concentration is given in Table 2 , which also shows the errors in predicting plasma concentrations from those of saliva using the least squares regression equations.

\section{Discussion}

Saliva has been substituted for plasma in the therapeutic monitoring and in pharmacokinetic studies of a number of drugs. Its collection with or without prior stimulation of flow is considered to be convenient, painless, and non-invasive. The saliva concentration of some drugs is similar to that of the free fraction in plasma and so its use represents a further advantage over methods using plasma.

The usefulness of saliva in monitoring theophylline treatment remains unproved, and conclusions in the published reports are conflicting. Most of these have described saliva/plasma theophylline relation in large groups of patients and few have looked at intrasubject variation during one dose interval, at different plasma concentrations, or over intervals of time.

A number of possible causes for large inter- and intrasubject variation have been suggested. Saliva flow rate did not affect the saliva/serum ratio in adults reported by Culig et al, ${ }^{8}$ but seemed to minimise variation in the saliva/plasma ratio in another group. We found no effect and no significant difference between stimulated and unstimulated samples. The use of a mucous extractor, however, to obtain 'unstimulated' saliva may in 
Table 2 Relation between saliva type and plasma concentration and the error in predicting plasma concentrations from saliva

\begin{tabular}{|c|c|c|c|c|c|c|}
\hline \multirow[t]{2}{*}{ Sample } & \multirow{2}{*}{$\begin{array}{l}\text { No of } \\
\text { samples }\end{array}$} & \multirow{2}{*}{$\begin{array}{l}\text { Correlation coefficient } \chi \mathrm{v} \\
\text { plasma concentration }\end{array}$} & \multirow[t]{2}{*}{ Pvalue } & \multicolumn{3}{|c|}{ Error in predicting plasma concentration (as $\%$ of all predictions) } \\
\hline & & & & $\leqslant 1 m g / l$ & $\leqslant 2 m g / l$ & $>2 \mathrm{mg} / \mathrm{l}$ \\
\hline Stimulated saliva & 125 & 0.84 & $<0.001$ & 23 & 54 & 46 \\
\hline All saliva & 224 & 0.79 & $<0.001$ & 16 & 43 & 57 \\
\hline
\end{tabular}

$\chi=$ Concentration of sample type.

Conversion-traditional units to SI: theophylline $1 \mathrm{mg} / \mathrm{I} \approx 5 \cdot 56 \mu \mathrm{mol} / \mathrm{l}$.

itself be stimulatory, and repeat specimens, albeit unstimulated, collected before stimulated ones may by Pavlovian effect be representative of stimulated saliva. The effect of $\mathrm{pH}$, reported to be negligible by Levy $e t l^{5}$ was not considered in this study, and the lack of $\mathrm{pH}$ effect has recently been confirmed by Knott et al. ${ }^{9}$

The mean saliva/plasma ratio in all samples in this study $(0.49)$ was similar to that found by other authors, and the highly significant correlation coefficient of $0.79(\mathrm{P}<0.001)$ between all samples of saliva and plasma seems to suggest that substitution of saliva for plasma may be reasonable. The wide interand intrasubject variation, however, in the saliva/ plasma ratio, unaccounted for by the type of sample collection, volume, or whether the timing follows single dose or represents steady state, proves otherwise.

Although standardisation within a centre, expertise in collection, and great attention to mouth hygiene and cleansing may be expected to reduce the saliva/plasma variation, one of us (GWR) now has personal experience of collecting over 2000 saliva specimens of different type, and, in spite of a consistent thorough approach, the wide variation is evident in this study.

Variation in plasma protein binding may account for some variation in free fraction and hence the saliva/plasma ratio, but our within patient values are of such magnitude as to almost discount this explanation.

There is no available information on the direct relation between saliva theophylline concentrations and clinical effect. No therapeutic range for saliva theophylline concentration has therefore been determined. In practice saliva concentrations have been used by clinicians as an indirect measure of the plasma drug concentration using the plasma therapeutic range proportionately changed according to an assumed consistent saliva/plasma concentration ratio. These results show that the use of saliva as an indirect means of monitoring plasma theophylline concentrations in children and so forming a basis for dose modification should not become routine prac- tice as the predictive error for plasma concentration is greater than $2 \mathrm{mg} / \mathrm{l}$ in over half the samples. In the search for an accurate non-invasive alternative to plasma concentrations it will be necessary to determine the relation between the concentrations in the medium used and to devise an optimum therapeutic range for that medium. We question whether the use of mucous extractors, citric acid crystals, and repeated saliva sampling might not prove as invasive as the use of plasma. For repeated sampling, as in kinetic studies, six of our seven patients (those 4 years and over) would prefer the placement of an indwelling intravenous cannula with subsequent drawing of samples through it, to that of repeated saliva stimulation and collection as described here-provided that only one intravenous access is required!

\section{References}

1 Mitenko PA, Olivie RI. Rational intravenous doses of theophylline. N Engl J Med 1973;289:600-3.

2 Weinberger MM, Bronsky EA. Evaluation of oral bronchodilator therapy in asthmatic children. J Pediatr 1974;84:421-7.

3 Rylance GW. Monitoring saliva anticonvulsant levels in children. Dev Med Child Neurol 1979;21:387-90.

4 Koysooko R, Ellis EF, Levy G. Relationship between theophylline concentration in plasma and saliva of man. Clin Pharmacol Ther 1974;15:454-60.

5 Levy G, Ellis EF, Koysooko R. Indirect plasma-theophylline monitoring in asthmatic children by determination of theophylline concentration in saliva. Pediatrics 1974;53:873-6.

6 Jackson AH, Edwards C, Cope AS, Stockley RA, Purkiss R. Reproducibility of saliva and plasma theophylline levels following single dose administration of two sustained release preparations. Br J Clin Pharmacol 1983;15:407-10.

7 Boobis S, Trembath PW, Chambers R, Edmunds AT. Salivary theophylline estimations: are they valid substitutes for plasma levels? Ther Drug Monit 1979;1:485-93.

8 Culig J, Johnston A, Turner P. Saliva theophylline concentrations after a single oral dose. Br J Clin Pharmacol 1982;13: 243-5.

${ }^{9}$ Knott C, Bateman M, Reynolds R. Do saliva concentrations predict plasma unbound theophylline concentrations? A problem re-examined. Br J Clin Pharmacol 1984;17:9-14.

Correspondence to Dr G W Rylance, Children's Hospital, Birmingham B16 8ET.

Received 30 July 1984 